\title{
An effective device for rumen cannulation in sheep
}

\author{
M. Abdel-Fattah ${ }^{1}$, A. M. Sedeek ${ }^{1}$, A. I. A. Suliman ${ }^{2}$ \\ ${ }^{1}$ Surgery, Anesthesiology and Radiology Department. Faculty of Veterinary Medicine, Beni-Suef \\ University and ${ }^{2}$ Animal Production Research Institute, Giza, Egypt.
}

\begin{abstract}
Presently neither the specification of rumen cannula for small ruminants is reported nor is it commercially available in Egyptian market. Therefore, fabrication of ruminal cannula for sheep and surgical procedure for its implantation are described in this paper. The device was adapted to allow sampling of entire ruminal contents via cannulas with different diameters, which tightly sealed within ruminal fistula to ensure cleaner, achieve easier nursing of operated animals, and maintain more normal ruminal environment. The ruminal cannula was applied into the sheep by one-stage operation. It has been successfully used in 11 ram (3-5 year-old) for 16 months without problems and caused no complications.
\end{abstract}

Fistulation and cannulation of the rumen is an integral part of the bovine and ovine nutritional studies. It is also recommended as conservative treatment in cases of chronic bloat (Anderson, et al., 1976). Thus, a need for successful durable ruminal fistulation and cannulation technique is often met with both in the research field as well as in the day to day practice (Schnautz, 1957; Wakanker, et al., 1980).

Many factors complicate ruminal fistulation and cannulation by conventional methods; accordingly various modifications in the processing of ruminal cannulas as well as fistulation techniques have been recorded to minimize complications (Schnautz, 1957; Wayne, et al., 1959; Komarek, et al., 1961; ElMonzaly, 1975; Corley, et al., 1999; Nocek, et al., 2002).

A single-stage ruminal fistula technique was quite successful in sheep while two-stage technique was recommended in cattle (Dougherty, 1981; Hassanein, et al., 1988). However, several types of ruminal cannula and respective surgical techniques have been reported by Brown, et al., (1968); Santra, et al., (2002). Ruminal cannulas were made of plastic, rubber, or even metal materials that should be placed and fixed properly to prevent leakage (Hecker, 1974; Thyfault, et al., 1975; Dougherty, 1981).

Ruminal fistulation and cannulation was adopted practically for obtaining samples of ruminal ingesta, fluid, or gases (Schnautz, 1957; Komarek, et al., 1961; Corley, et al., 1999).

Fistulated animals maintained functioning satisfactorily for about 10 months to 12 years (Nangeroni, 1954; Wakanker, et al., 1980).

\section{Materials and methods}

Animal model. Ruminal fistulation and cannulation was performed on 11 healthy rams of native breed of 3-5 year-old, and ranged in weight between $40-65 \mathrm{~kg}$.

Preoperative preparation. Food was withheld for 24 hours, while water was withheld for 12 hours, prior to surgery. The left para-lumber region was prepared for aseptic surgery. The operation was carried out in recumbent position and the operated animals were positioned on the right side.

Anesthesia. Operated animals were injected intravenously with Diazepam $0.5 \%$ in a dose of 2 $\mathrm{mg} / \mathrm{kg}$ B. wt., 10 minutes later; animals were injected, slowly intravenous, with thiopental sodium $2.5 \%$ in a dose of $10 \mathrm{mg} / \mathrm{kg}$ B.wt. (Abdel-fattah, 1999).

Fabricated cannula. The cannula used in this technique was made of the upper part of polypropylene plastic bottle with its screwed cap, four pairs of small button-like plastic pieces, and strong non absorbable suture material (silk). The upper part of different sizes polypropylene plastic bottle was cut off in such way as to include the neck and part of the flange of the top of the bottle. This part of the bottle was stoppered by screwed cap. 
With respect to small cannula, diameter of external opening was $4 \mathrm{~cm}$, diameter of internal opening was $7.5 \mathrm{~cm}$, and its weight was $28 \mathrm{gm}$ (Fig. 1). On the other hand, the diameter of the external opening of the large cannula was $7 \mathrm{~cm}$, the diameter of the internal opening was $12 \mathrm{~cm}$, and the weight of the cannula was 35 gm (Fig. 2). The stopper of the cannula could be modified by fixing a rubber tube to its center for sampling of gases (Fig.3).

For good fixation, 2-4 button-like plastic pieces (according to the size of operated animal) were placed in the inner aspect of the main piece of the cannula and threaded by silk suture materials to another four plastic pieces out side the body. Figure (4) shows the final shape of the cannula.

Surgical technique. An initial skin incision was made few centimeters inferior to the tuber coxae and extended ventrally. The length of skin incision, as well as the underlying layers included the ruminal incision, was made large enough for insertion of the cannula (Fig. 5).

Another ruminal incision was made $7-10 \mathrm{~cm}$ cranial to the original one. It was created parley wide for the neck of the cannula to be exteriorized through it.

The cannula was positioned into the rumen through the initial incision and pushed from inside the rumen through the second ruminal incision, and 4-6 interrupted sutures were stitched through the rumen and cannula by silk, then a purse string suture was sewed around the edge of the second ruminal incision and was drawn tight and tied around the neck of the cannula (Fig. 6, 7).

The initial ruminal incision was closed as usual and the rumen was repositioned into the peritoneal cavity.

The skin and subcutaneous tissue, $7-10 \mathrm{~cm}$ cranial to the initial incision, were bluntly dissected from the abdominal muscles and a circular excision was made through the muscles and peritoneum. The excision in the muscles and peritoneum created a hernial ring that was wide enough to force the cannulated part of the rumen through it. The herniated part of the cannulated rumen with its cannula was forced through the hernial-like ring, and then continuously sutured around the contour of the cannula with the muscles and peritoneum.

A second skin incision was made corresponding to outer opening of the cannula. This skin incision was created parley enough for the neck of the cannula to be forced through it.
Then 4-6 staying stitches were made around the neck of the cannula, between skin and underlying herniated rumen (Fig.8).

A purse string suture was sewed around the edge of skin incision via subcutaneous layer and was drawn tight and tied around the neck of the cannula (Fig. 9).

The initial incision through the skin, muscle and peritoneum was sutured as usual.

2-4 pairs of fixation buttons were implanted inside the cannulated rumen and outside the body, through the outer opening of the cannula, around the contour of the cannula, by using silk, and then they were perfectly tighten and tied (Fig. 8, 9).

Following operation, animals were isolated, fasted for another 12 hours, administered intravenous fluid therapy, intramuscular long acting oxytetracycline, the wounds were dressed with povidone iodine (Fig. 10), food intake was restricted up to one week post surgery to avoid complications, and finally the skin sutures were removed 10 days post surgery.

\section{Results}

Fastening of the animals prior to surgery reduced ruminal contents and facilitated surgical interference.

Complete muscular relaxation could be achieved after intravenous injection of diazepam and thiopental sodium, and the duration of anesthesia lasted about 90 minutes, followed by smooth uncomplicated recovery.

Light polypropylene flexible cannulas (28-35 gm) facilitated its insertion, exteriorization, and fixation and caused no mechanical pain for the operated animalsThe average time of the operation from the initial skin incision till the final exteriorization and fixation of the cannula was 55 minutes (50-60 minutes). Cannulas were successfully implanted within the ruminal fistula of 11 ram ( 5 animals by small cannulas, and 6 animals by large cannulas). The operated animals followed up for 60 days (Fig. 11, 12). The initial surgical wound showed healing with first intension within 10 days without post surgical problems in any of the operated animals, except presence of temporary slight edema and thickening around the cannula in three animals, and death of one animal due to causes unrelated to surgery, rest of the animals enjoyed good health through the period of experiment (16 months). The cannula was kept in place without any problems, caused no complications or leakage around it; and it remained gas and liquid tight over the period of experiment. 


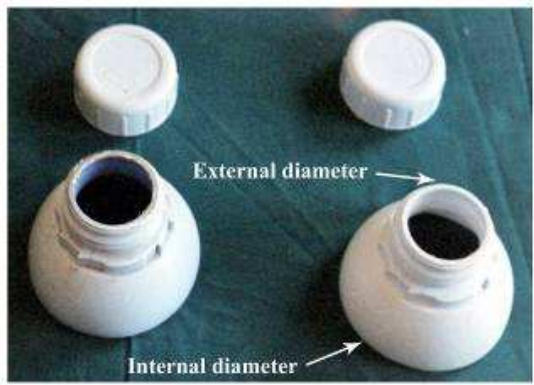

Figure (1)

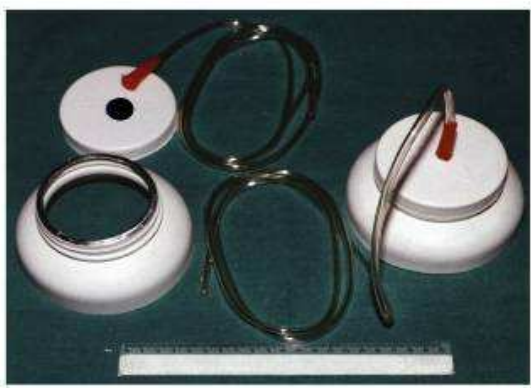

Figure (3)

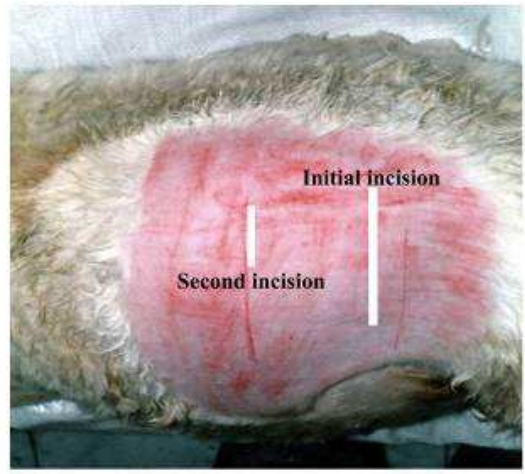

Figure (5)

Discussion

Our observations in this study indicated that excessive preoperative preparation reduced the size of the rumen too much to be manipulated and facilitated aseptic surgery. This coincides with Wakanker, et al., (1980) who stated that fastening prior to surgery reduced the load of rumen that facilitated healing of the organ and reduced chance of soiling of the surgical field with ruminal contents during surgery.

Intravenous injection of diazepam that was followed by thiopental sodium ensured sedation, analgesia, complete muscular relaxation, and control of visceral reflex to efficient and satisfactory levels to perform laparotomy (Tantawy, 1978; Ragab, 1989).

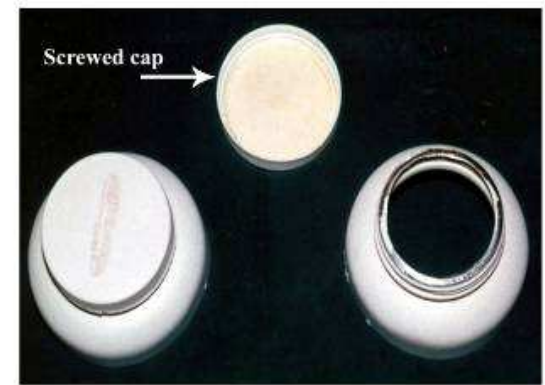

Figure (2)

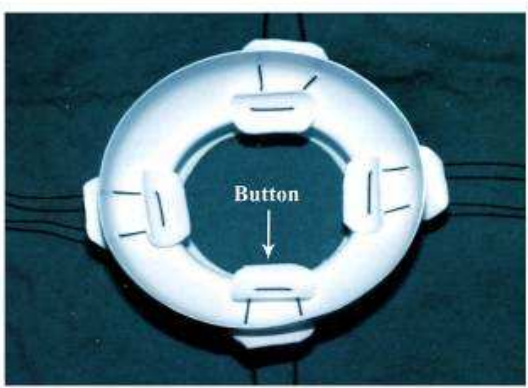

Figure (4)

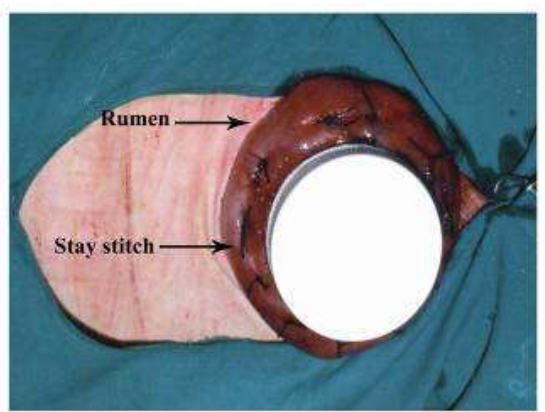

Figure (6)

Exteriorization of the cannula through a second incision, which fitted exactly to its diameter, favored healing of the initial incision by first intension and prevented leakage between the rumen and abdominal wall (El-Monzaly, 1975).

Exteriorization of the cannulated part of the rumen from peritoneal cavity via a second circular abdominal wound and suturing of the prolapsed part of the rumen, peritoneum, and abdominal muscles around the contour of the cannula to induce incarcerated hernia, ensured mechanical support to the cannula (Venugopalan, 1986).

The purse string suture effectively sealed the peritoneal cavity around the level of the cannula as evidenced by absence of peritonitis, on the 


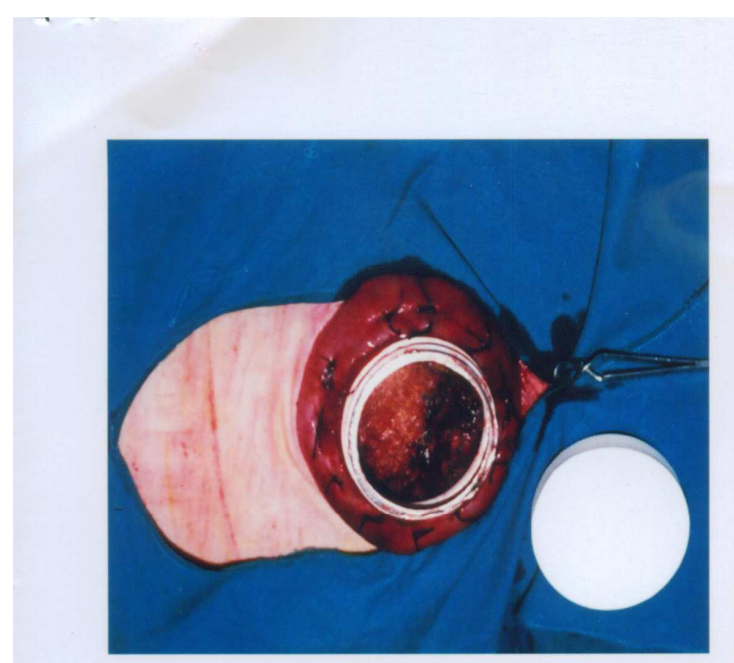

Figure (7)

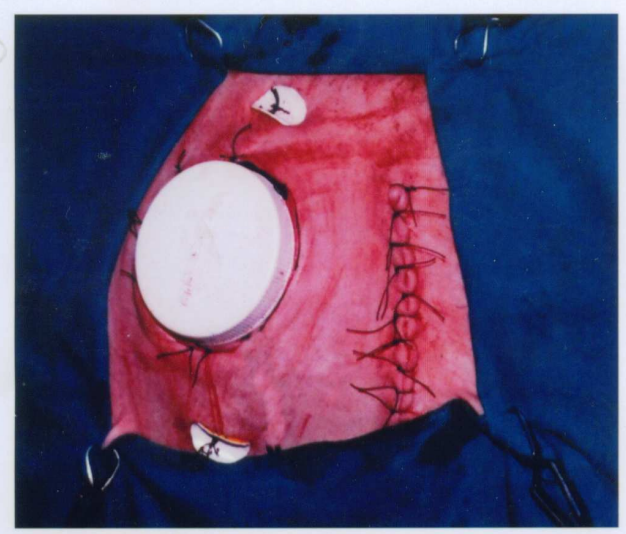

Figure (9)

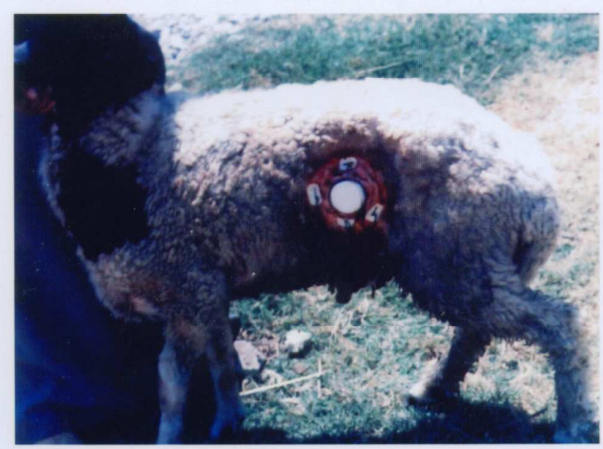

Figure (11)

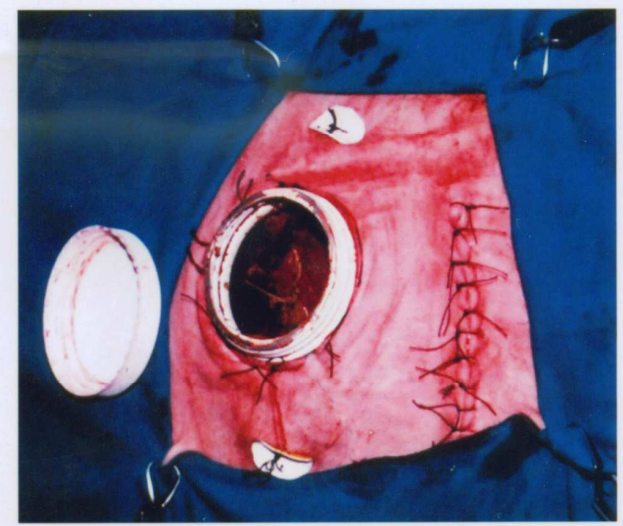

Figure (8)

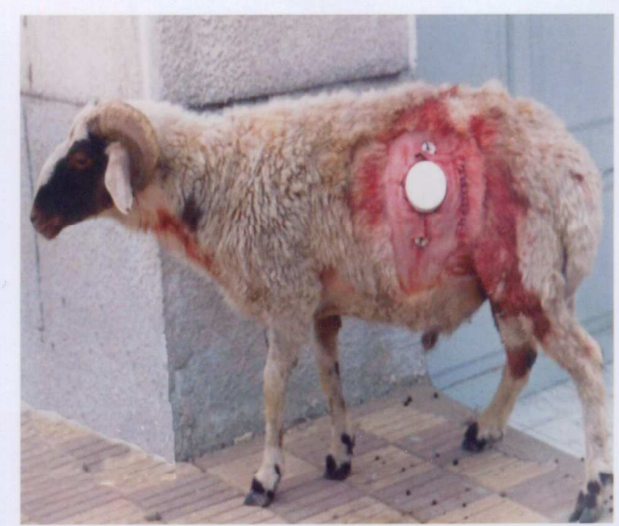

Figure (10)

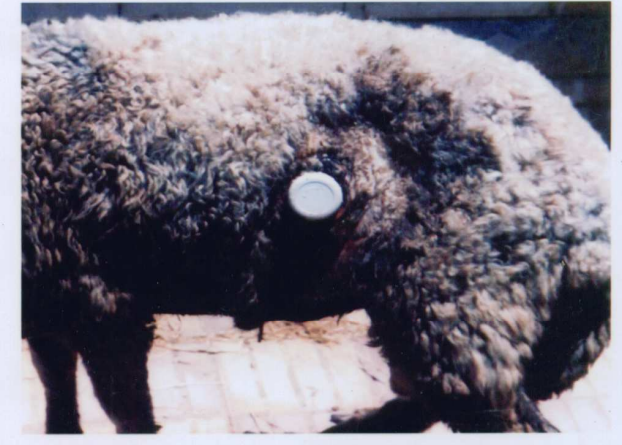

Figure (12) other hand, Wakanker, et al., (1980) mentioned that the through-and-through sutures increased the area of adhesion as expected and prolonged the operative procedure.

Slightly smaller incisions of the rumen and skin than the size of neck of the cannula are preferred, that made the rumuinal opening and exposure skin opening fit tightly around the neck of the cannula (Schnautz, 1957; El-Monzaly, 1975).

A purse string sutures around the neck of the cannula tends to curl the edges of the rumen and the skin inward ensuring that the ruminal serosa will come in contact with the cut edges of the skin and subcutaneous layer to provide perfect adhesion and to strangulate the neck of the 
cannula to support it (Komarek, et al., 1961). Placing of 2-4 fixation buttons inside the concha of the cannula and fixation of them by silk to another four buttons over the skin provided tight contact between cannulated part of rumen and abdominal wall as well as ensured mechanical support to the cannula (Misra, et al., 1981; Buckner, 1995).

Light weight of the cannula as well as short protruded part of it (1-1.5 cm neck length) through the flank, rarely subjected it to mechanical disturbances (Komarek, et al., 1961).

This fabricated cannula is cheap, applicable, durable, and available; causes no mechanical pain; and maintains normal ruminal environment. This technique of ruminal fistulation and cannulation is simple, easy, with minimal time consuming (one-stage operation), suitable for collection of all ruminal contents, and has no adverse effect on general health condition, so it is advised to be adopted in small ruminants.

\section{References}

Abdel-fattah, M. (1999): The goat as a model for experimental surgery. $\mathrm{Ph}$. D. thesis, surgery, anesthesiology, and radiology, Fac. Vet. Med., Cairo Univ., Beni-Suef branch, Egypt.

Anderson, J. F. and Frederikson, E. D. (1976): Surgical fistula as and aid in the treatment of chronic bloat in cattle. Vet. Med. Small Anim. Clin., 1363-1367.

Brown, G. F.; Armstong, D. G.; and MacRac, J. C. (1968): The establishment in one operation of cannula into the rumen and re-entrant cannula into the duodenum and ileum of the sheep. British Vet. J., 124: 78-81.

Buckner, R. (1995): Surgical correction of left displaced abomasums in cattle. Vet. Rec., 136, 265-267.

Corley, R. N.; Murphy, M. R.; Lucena, J.; and Panno, S.V. (1999): Technical note: A device for obtaining Time integrated samples of ruminal fluids J. Anim. Sci., 77: $2540-2544$
Dougherty, R. W. (1981): Experimental surgery in farm animals. The Iowa state university press/ Ames, Iowa, 50010. 1st ed.

El-Monzaly, M. (1975): Simplified surgery for rumen cannulation of goats under the influence of Rumpun. J. Egypt. Vet. Med. Assoc., 35(3): 207-218.

Hassanein, A. ; Soliman, A. S.; and Eifat, J. F. (1988): Rumen cannulation in sheep. Alex. J. Vet. Sci., 4(2): 429435.

Hecker, J. F. (1974): Experimental surgery on small ruminants. Butterworths \& Co, Ltd, London, England

Komarek, R. J. and Leffel, E. C. (1961): Gas-tight cannula for rumen fistula. J. A. Sci., Vol. 20 No. 4, 982984. Misra, S. S. and Angelo, S. J. (1981): Vaginopexy technique for the management of recurrent utero vaginal prolapse in bovinesInd. Vet. J., 58:576-580.

Nangeroni, L. L. (1954): A steer with a twelve-year old rumen fistula. JAVMA, 125: 451-452.

Nocek, J. E.; Allman, J. G.; and Kautzw, P. (2002): Evaluation of an indwelling ruminal probe methodology and effect of grain level on diurnal $\mathrm{pH}$ variation in dairy cattle J. Dairy Sci., 85 (2): 422-428.

Ragab, G. A. (1989): Some studies on the surgery of the urogenital system in small ruminants. Ph. D. thesis, Fac. Vet. Med., Cairo Univ., Egypt.

Santra, A. and Karim, S. A. (2002) Rumen cannulation in sheep and goats: Fabrication of cannula and surgical procedure for its implantation. Ind. J. Anim. Sci., 72(11): 978-980.

Schnautz, J. O. (1957): A rumen fistula modification. Am. J. Vet. Res., 18: 73-75.

Tantawy, M. (1978): Studies on the effect of some anesthetics in sheep and goats. Ph. D. thesis Vet. Surg. Assuit Univ., Egypt.

Thyfaultt, H. A.; Leffel, E. C.; and Huang, M. D. (1975): Simplified method for producing permanent rumen fistula. J. Dairy Sci., 58: 1899-1901.

Venugopalan, A. (1986): Essentials of veterinary surgery. 5th ed., Oxford and IBH publishing Co. PVT. L.T.D.; New Delhi-Bombay.

Wakanker, C. C.; Mantri, M. B.; and Deshpande, K. S. (1980): A study on evaluation of rumen fistulation techniques in bovines. Indian Vet. J., 57:160-163.

Wayne, B. and Lynn, F. J. (1959): A plastic rumen fistula apparatus for sheep - its insertion and use. JAVA, 15: 603605.

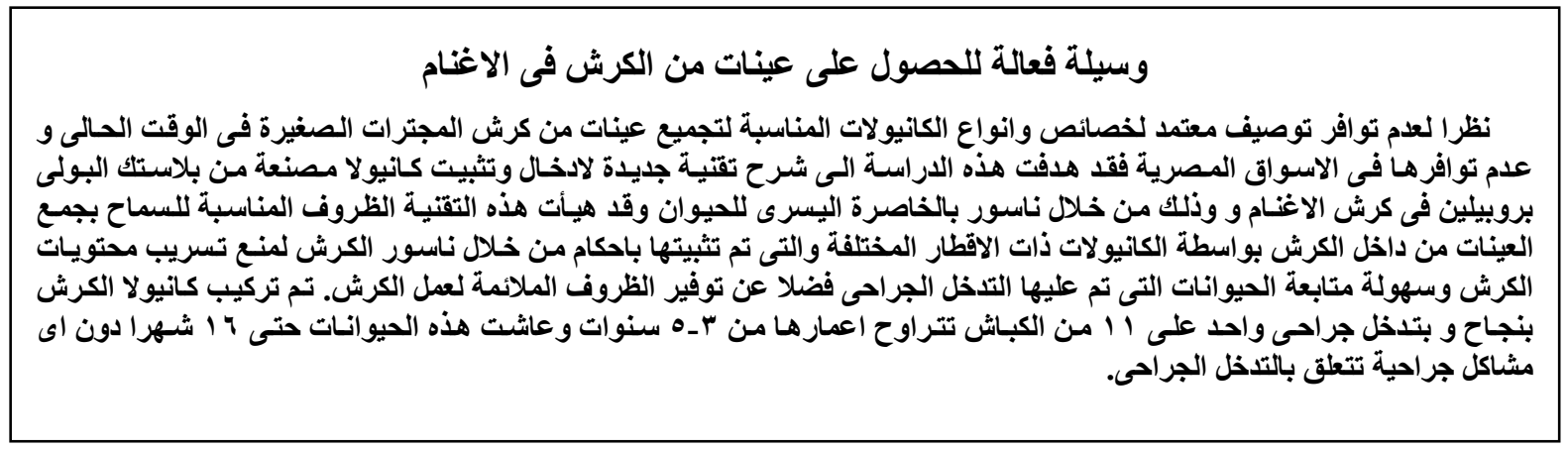


